\section{Commentary: Respect idiopathic pulmonary hypertension...or urine trouble}

\section{Jacob A. Klapper, MD, FACS}

When I walk through the intensive care unit, I can't think of another piece of equipment that portends a more ominous outcome than a dialysis machine. Its mere presence generally signifies that this particular patient's postoperative course has not proceeded as anticipated. Similarly, as a transplant surgeon, I have equal respect for the complexity of taking care of those rare patients with idiopathic pulmonary hypertension (iPAH). This is not a common disease subtype among any center's yearly transplant volume, and their unique cardiovascular physiology demands careful thought and consideration.

For these reasons, I read with real interest the Vienna group's approach to iPAH in the intraoperative and postoperative setting. ${ }^{1}$ Central to this paper's message is that these patients, unlike their peers, possess an untrained left ventricle (LV) that is at risk for overload secondary to normalization of pulmonary vascular resistance. Consequently, the group is liberal with their use of venoarterial extracorporeal membrane oxygenation postoperatively, and, as an adjunct, the early implementation of continuous renal-replacement therapy (CRRT). Again, it is important to emphasize that CRRT was being implemented not specifically based on renal function but rather fluid balance and a desire to control LV preload.

As the authors demonstrate, in a significant percentage of patients, venoarterial extracorporeal membrane oxygenation will provide ample LV support, and volume status can be managed with diuretics. As shown in the CRRT cohort, however, a subset of patients will have diminished

\footnotetext{
From the Division of Cardiothoracic Surgery, Duke University Medical Center, Durham, NC.

Disclosures: The author reported no conflicts of interest.

The Journal policy requires editors and reviewers to disclose conflicts of interest and to decline handling or reviewing manuscripts for which they may have a conflict of interest. The editors and reviewers of this article have no conflicts of interest.

Received for publication May 29, 2021; revisions received May 29, 2021; accepted for publication June 1, 2021; available ahead of print June 24, 2021.

Address for reprints: Jacob A. Klapper, MD, FACS, Division of Cardiothoracic Surgery, Duke University Medical Center, DUMC 3954, Durham, NC 27710 (E-mail: Jacob.klapper@duke.edu).

J Thorac Cardiovasc Surg 2022;163:536-7

0022-5223/\$0.00

Published by Elsevier Inc. on behalf of The American Association for Thoracic Surgery

https://doi.org/10.1016/j.jtcvs.2021.06.007
}

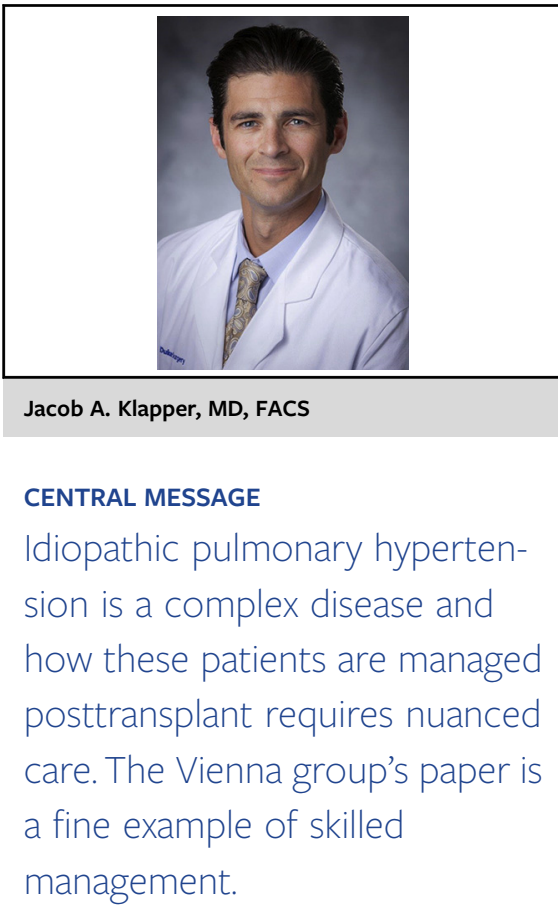

renal function before transplant and for these individuals, diuretic therapy may not be sufficient. Therefore, another salient element of this article is that preoperatively identifying these patients and being prepared for the initiation of CRRT early can have real benefits. I can anticipate, at least where I practice, that this treatment philosophy will require some convincing among my nephology colleagues, but, that fact is again, why this paper can be so influential.

Ultimately, the goal of the approach described here is that the allograft is protected. The majority of the patients who comprised this cohort were young, and it would be expected that their LVs would compensate and remodel quickly. Transplanted lungs, however, are predictably less forgiving, and an overwhelmed LV can lead to pulmonary edema and presumably other forms of acute lung injury that negatively impact long-term graft function and survival. Thus, the ultimate gauge of the success of the Vienna group's algorithm is the $70 \%$ survival 10 -year survival rates.

Like a good movie or book, this is a paper that is likely to remain tucked in my memory. That said, I do have some slight criticisms/caveats. First, acquired pulmonary hypertension in the patient with idiopathic pulmonary fibrosis is not $\mathrm{PAH}$, and management of these patients postoperatively should not necessarily mirror the approach highlighted here. Second, the patients in this cohort were all young, and their capacity for renal recovery is much 
greater than say that of a patient with idiopathic pulmonary fibrosis in their $60 \mathrm{~s}$ or $70 \mathrm{~s}$. In the end, however, the message is clear: respect idiopathic pulmonary hypertension or urine trouble.

\section{Reference}

1. Benazzo A, Bajorek L, Morscher A, Schrutka L, Schaden E, Klepetko W, et al Early implementation of renal replacement therapy after lung transplantation does not impair long-term kidney function in patients with idiopathic pulmonary arterial hypertension. J Thorac Cardiovasc Surg. 2022;163:524-35.e3.
See Article page 524.

\section{Commentary: The perfidious left ventricle in pulmonary hypertension}

\author{
Max K. H. Wong, MBBS, and \\ Michael K. Hsin, MD, FRCS CTh
}

Early postoperative left ventricle (LV) dysfunction following bilateral lung transplant (LTx) in patients with pulmonary arterial hypertension (PAH) is a wellrecognized and complex challenge. ${ }^{1}$ It has been shown to occur in up to one third of LTx recipients for PAH, causes early morbidity, and contributes to the development of primary graft dysfunction. ${ }^{2,3}$

In this issue of the Journal, Benazzo and colleagues ${ }^{4}$ describe the Vienna experience, spanning 18 years with restrictive fluid management after double LTx in patients with idiopathic PAH, namely a liberal policy of early implementation of continuous renal-replacement therapy (CRRT) when a negative fluid balance could not be achieved despite maximal medical therapy. This is irrespective of levels of creatinine, blood urea nitrogen, or glomerular filtration rate. The authors concluded early CRRT did not impair long-term kidney function, and postoperative CRRT was not a risk factor for mortality.

In patients with pulmonary hypertension, the elevated pulmonary vascular resistance represents an increased afterload to the right ventricle (RV) and causes remodeling,

\footnotetext{
From the Department of Cardiothoracic Surgery, Queen Mary Hospital, Hong Kong SAR, China.

Disclosures: The authors reported no conflicts of interest.

The Journal policy requires editors and reviewers to disclose conflicts of interest and to decline handling or reviewing manuscripts for which they may have a conflict of interest. The editors and reviewers of this article have no conflicts of interest.

Received for publication May 31, 2021; revisions received May 31, 2021; accepted for publication June 1, 2021; available ahead of print June 25, 2021.

Address for reprints: Michael K. Hsin, MD, FRCS CTh, Department of Cardiothoracic Surgery, Queen Mary Hospital, Room 308, New Clinical Building, Pok Fu Lam, Hong Kong, Hong Kong SAR, China (E-mail: mkhsin@hotmail.com).

J Thorac Cardiovasc Surg 2022;163:537-8 0022-5223/\$36.00

Copyright (C) 2021 Published by Elsevier Inc. on behalf of The American Association for Thoracic Surgery

https://doi.org/10.1016/j.jtcvs.2021.06.001
}

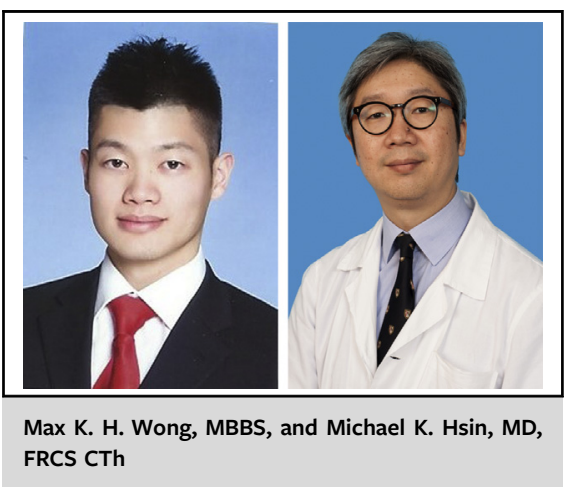

CENTRAL MESSAGE

Aggressive management of the volume status with renalreplacement therapy should be considered in the management of LV dysfunction after lung transplant in pulmonary arterial hypertension patients.

initially with hypertrophy and eventually dilatation. This results in a spherical-shaped RV, increased RV wall stress, impaired contractility, and progressive tricuspid regurgitation. Together, these further reduce the effective cardiac output of the RV.

In patients with $\mathrm{PAH}$, magnetic resonance imaging studies have shown reduced LV pump function. LV dysfunction in PAH is caused by (1) direct ventricular interaction, where the interventricular septum is bowing leftward, thus limiting LV diastolic filling; and (2) hemodynamic effects from a decrease in RV output, causing reduced LV filling. Human cardiac biopsy samples taken from heart/lung transplant recipients revealed that LV cardiomyocytes in patients with PAH have smaller crosssectional area, indicating atrophy; reduced forcegenerating capacity, which is partially caused by the loss of major contractile protein myosin; and reduced phosphorylation levels of key sarcomeric proteins. ${ }^{6}$ Biopsy samples 